\title{
cyclic GMP Mediated Inhibition of Spontaneous Germinal Vesicle Breakdown Both with and without Cumulus in Mouse Oocyte
}

\author{
Heekyung Hwang and ${ }^{\dagger}$ Yong-Pil Cheon \\ Department of Biology, Institute Basic Sciences, Sungshin Women's University, Seoul, Korea
}

\begin{abstract}
Intact germinal vesicle (GV) arrest and release are essential for maintaining the fertility of mammals inducing human. Intact germinal vesicle release, maturation of oocytes is maintained by very complex procedures along with folliculogenesis and is a critical step for embryonic development. Cyclic guanosine monophosphate (cGMP) has been suggested a key factor for meiotic arrest but so far its mechanisms are controversy. In this study we examine the effects of cGMP on germinal vesicle breakdown in cumulus-enclosed oocytes and denuded oocytes. Spontaneous maturation was inhibited by a cGMP agonist, 8-Br-cGMP with concentration dependent manners both in cumulus-enclosed oocytes and denuded oocytes. The inhibitory effect was more severe in denuded oocytes than cumulus-enclosed oocytes. The Rp-8-Br-cGMP and Rp-pCPT8-Br-cGMP did not severely block GVB compared to 8-Br-cGMP. The spontaneous GVB inhibitory effects were different by the existence of cumulus. Based on them it is suggested that the cumulus modulates the role of cGMP in GV arrest.
\end{abstract}

Key words : Germinal vesicle breakdown, cGMP

\section{INTRODUCTION}

The meiotic cell cycle in mammalian oocytes proceeds up to the diplotene or dictiate stage of the first prophase and stay at this phase before LH surge (Hubbard \& Terranova, 1982; Dutta et al., 2016). During growth phase of the follicle, the oocyte remains the arrested condition at prophase I. At this time it is incompetent to complete meiosis. The germinal vesicle intact oocytes in cumulus-oocyte-complex removed from mature antral follicles spontaneously progress to the metaphase II stage by culture without gonadotropin (Pincus \& Enzmann, 1935; Erickson $\&$ Sorrenson, 1974). On the other hand, the oocytes enclosed in an antral follicle, do not enter meiosis even though these follicles are removed from their environment. By the adding of gonadotropin or releasing from follicle the oocyte resume meiosis. Therefore, some low molecular weight substances in the follicular fluid have been suggested as a mediator for meiotic arrest (Eppig et al., 1985; Cheon, 2004, Hwang \& Cheon, 2013).

Cyclic adenosine monophosphate (cAMP) is a key signaling mediator in oocyte for meiotic prophase arrest in most species studied. Elevated cAMP concentration in the oocyte has been demonstrated to maintain meiotic arrest and a transient decrease in cAMP levels in the oocytes is thought to be a primary trigger for resumption of meiosis. cAMP works through protein kinase A (PKA)-mediated phosphorylation of maturation promoting factor (Jones,

\footnotetext{
Manuscript received October 25, 2016, Received in revised form November 25, 2016, Accepted December 19, 2016

† Corresponding Author : Yong-Pil Cheon, Department of Biology, College of Natural Sciences, Sungshin Women's University, 249-1 Dongseon-dong 3ga, Seongbuk-gu, Seoul 136-742, Korea, Phone: 82-2-920-7639, Fax: 82-2-920-2093, e-mail: ypcheon@sungshin.ac.kr
}

This is an Open Access article distributed under the terms of the Creative Commons Attribution Non-Commercial License (http:// creativecommons.org/licenses/by-nc/3.0) which permits unrestricted non-commercial use, distribution, and reproduction in any medium, provided the original work is properly cited. 
2008). The levels of cAMP can be modulated by the activity of cAMP phosphodiesterase, PDE3A in the oocyte (Hambleton et al., 2005). On the other hand, cAMP can be transported from the surrounding cumulus cells (Norris et al., 2009) or generated by oocyte itself through the activation of heterotrimeric $\mathrm{G}$ protein $\left(\mathrm{G} \alpha_{\mathrm{s}}\right)$-linked receptor, GPR3 or GRP12 G (Mehlmann, 2005).

In the case of cyclic GMP, it has been shown to increase in the whole ovaries in hamsters until the LH surge when cAMP rises and cGMP falls (Hubbard, 1980). cGMP works in maintaining of the meiotic arrest in oocyte and that this inhibition is dose and time dependent and expressed only in oocytes with intact cumulus (Jankowski et al., 1997; Zhang et al., 2010; Robinson et al., 2012; Egbert et al., 2014; Shuhaibar et al., 2015). It appears that the inhibitory action of cGMP on oocyte maturation is mediated by the cumulus oophorous while cAMP acts directly on the oocyte (Hubbard \& Terranova, 1982). However, so far, the essentiality of cumulus cells for cGMP in oocyte is controversy. Therefore, in the present study, we investigate whether the cGMP-mediated meiotic arrest can be possible without cumulus cells during in vitro culture.

\section{MATERIALS AND METHODS}

\section{Animals and oocyte collection}

CD1 mice were maintained on a $10 \mathrm{hr}$ light and $14 \mathrm{hr}$ dark cycle under standard vivarium condition and were supplied with food and water ad libitum. Immature female mice (20-24 days old) were injected with 5 IU of pregnant mares serum gonadotropin (PMSG; i.p.) to enhance multiple follicular development. PMSG primed mice are sacrificed after $46 \mathrm{hr}$ and obtained the ovary. Oocytes were collected by ovarian follicular puncture with a needle under a dissecting microscope. To get cumulus free GV oocyte, the cumulus mass were removed with a fine-bore pipetted. The entire procedure did within $20 \mathrm{~min}$ after puncture and only the healthy oocytes and cumulus-enclosed oocytes were chosen for examination. Cumulusoocyte complexes and oocytes were transferred into BWW medium containing $0.4 \% \mathrm{BSA}$ and cultured.

\section{Culture of treatment of chemical}

Oocytes (8-10 oocytes/drop) were cultured in $10 \mu \mathrm{L}$ drops of BWW in mineral oil (Sigma) or $15 \mathrm{hr}$ at $37^{\circ} \mathrm{C}$ in a humidified atmosphere conditioning $5 \% \mathrm{CO}_{2}$. The progression of meiotic maturation was scored by observing the breakdown of germinal vesicles (GVB) and the subsequent appearance of polar bodies with an inverted microscope. Cell permeable cGMP analogs, 8-Bromoguanosine 3',5' -cyclic monophosphate (8-Br-cGMP; $1 \mathrm{mM}$ or $1 \mathrm{M})$, Rp-8-Bromo-cGMPs (1 mM or $1 \mathrm{M}$ ), Rp-pCPT-8Bromo-cGMP (1 $\mathrm{mM}$ or $1 \mathrm{M})$ were treated into the medium and GV intact oocytes were cultured. The progression of meiotic maturation was scored by observing the breakdown of germinal vesicles (GVB) and the subsequent appearance of polar bodies with an inverted microscope.

\section{Statistical analysis}

Chi-squared test was used in statistical analysis, and a $P$ value less than 0.05 was considered significant.

\section{RESULTS}

\section{1. cGMP agonist inhibited meiotic resumption}

To know the difference of cGMP sensitivity to meiotic arrest by the existence of cumulus, cell permeable cGMP analog, 8-Bromoguanosine 3',5' -cyclic monophosphate (8Br-cGMP) was treated to GV intact oocytes as mentioned in Materials and Methods. GVB was inhibited concentration dependently by the 8-Br-cGMP in the cumulusenclosed oocyte (Fig. 1A). In addition, it also inhibited GVB in denuded oocytes with concentration dependent manner (Fig. 1B). At $6 \mathrm{hr}$ of incubation, the $\mathrm{GV}$ intact 


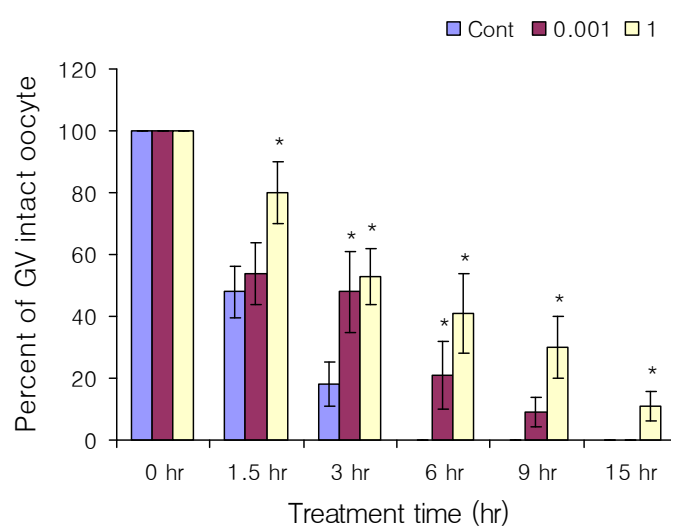

(A)

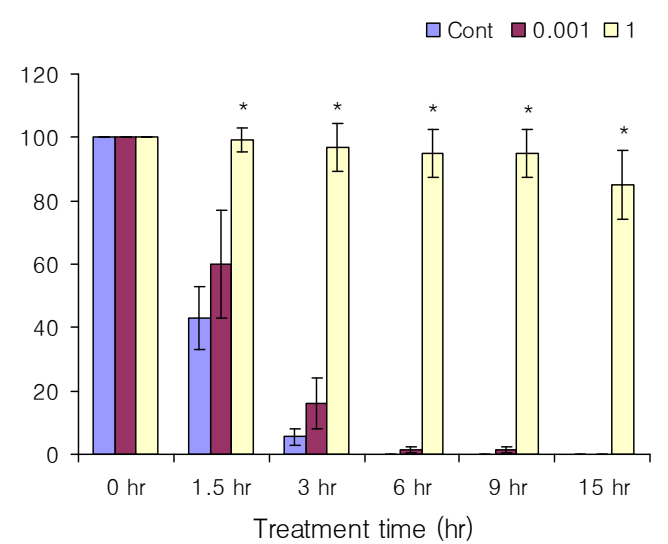

(B)

Fig. 1. GVB was severely inhibited by 8-Br-cGMP, a cGMP agonist in cumulus-enclosed oocytes (A) and denuded oocytes (B). GV oocytes were cultivated in medium containing $0.001 \mathrm{mM}$ or $1 \mathrm{mM} 8$ Br-cGMPs for $15 \mathrm{hr}$ and nuclear status were determined under the investigated microscope (Nomarski DIC modulated) at $0 \mathrm{hr}, 1.5 \mathrm{hr}, 3 \mathrm{hr}, 6 \mathrm{hr}, 9$ $\mathrm{hr}$ and $15 \mathrm{hr}$. GV, germinal vesicle. *: $P<0.05$ versus control.

percentage of cumulus-enclosed oocytes was $0 \%$ at control, $21 \%$ at $1 \mathrm{mM} 8$-Br-cGMP, and $41 \%$ at $1 \mathrm{M} 8$-Br-cGMP. On the other hand, in the case of denuded oocyte, the GV intact percentage was $0 \%$ at control, $1.4 \%$ at $1 \mathrm{mM} 8-\mathrm{Br}$ cGMP, and $95 \%$ at $1 \mathrm{M} \mathrm{8-Br-cGMP.} \mathrm{At} 15 \mathrm{hr}$ of incubation, the intact percentage was $0 \%$ at control, $0 \%$ at $1 \mathrm{mM} 8-\mathrm{Br}$ cGMP, and $11 \%$ at $1 \mathrm{~m} 8$-Br-cGMP. In the case of denuded oocyte, GV intact percentage was $0 \%$ both at control and 1
mM 8-Br-cGMP, and 85\% at 1 M 8-Br-cGMP.

The inhibitory effect of 8-Br-cGMP was more severe in denuded oocytes than cumulus-enclosed oocytes. At $1 \mathrm{M}$ 8-Br-cGMP, the GVB inhibition was significantly higher in denuded oocytes than cumulus-enclosed oocytes at all time points (Fig. 1).

\section{Effects of Rp-8-Br-cGMP and Rp-pCPT-8-Br- cGMP on GV arrest}

The cell permeable cGMP analog Rp-8-Br-cGMP and RP-pCPT-8-Br-cGMP but have a different function from 8Br-cGMP were treated to the GV intact oocytes. Rp-8-BrcGMp and Rp-pCPT-8-Br-cGMP have antagonistic effects in cGMP target cellular mediator, a cGMP-dependent protein kinase. In cumulus-enclosed oocyte, Rp-8-Br-cGMP did not block GVB (Fig. 2A). In denuded oocyte, it also did not block the GVB (Fig. 2B). However, there were no concentration dependent manners in GV arrest. At $6 \mathrm{hr}$ of culture, GV intact percentages in cumulus-enclosed oocytes were $0 \%$ both at control and $1 \mathrm{M}$ Rp-8-Br-cGMP, and $48 \%$ at $1 \mathrm{mM} \mathrm{Rp-8-Br-cGMP.} \mathrm{In} \mathrm{denuded} \mathrm{oocytes,} \mathrm{the}$ GV intact percentages were $4 \%$ at control, $70 \%$ at $1 \mathrm{mM}$ Rp-8-Br-cGMP, and 20\% at 1M Rp-8-Br-cGMP. At $15 \mathrm{hr}$ after culture, the GV arrest percentages in cumulus-enclosed oocytes were $0 \%$ both at control and $1 \mathrm{M} \mathrm{Rp}-8-\mathrm{Br}-$ cGMP, and $10 \%$ at $1 \mathrm{mM} \mathrm{Rp-8-Br-cGMP.} \mathrm{In} \mathrm{denuded}$ oocytes, the GV arrest percentages were $0 \%$ at control, 10 $\%$ at $1 \mathrm{mM} \mathrm{Rp}-8-\mathrm{Br}-\mathrm{cGMP}$, and $2.5 \%$ at $1 \mathrm{M} \mathrm{Rp}-8-\mathrm{Br}-$ cGMP (Fig. 2). Compared with the results of 8-Br-cGMP in denuded oocytes, the GVB blocking effects is high in 8Br-cGMP.

In the case of Rp-pCPT-8-Br-cGMP, its effect on GV arrest was stronger than Rp-8-Br-cGMP (Fig. 2 and 3). In cumulus-enclosed oocytes which were cultured in RppCPT-8-Br-cGMP containing media, the GV arrest percenttages were $0 \%$ at control, $43 \%$ at $1 \mathrm{mM} \mathrm{Rp-pCPT-8-}$ Br-cGMP, and 9.5\% at 1M Rp-pCPT-8-Br-cGMP after $6 \mathrm{hr}$ 


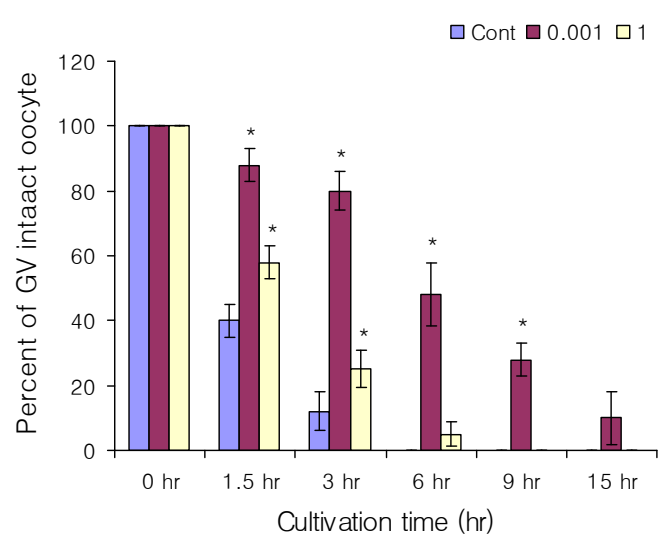

A

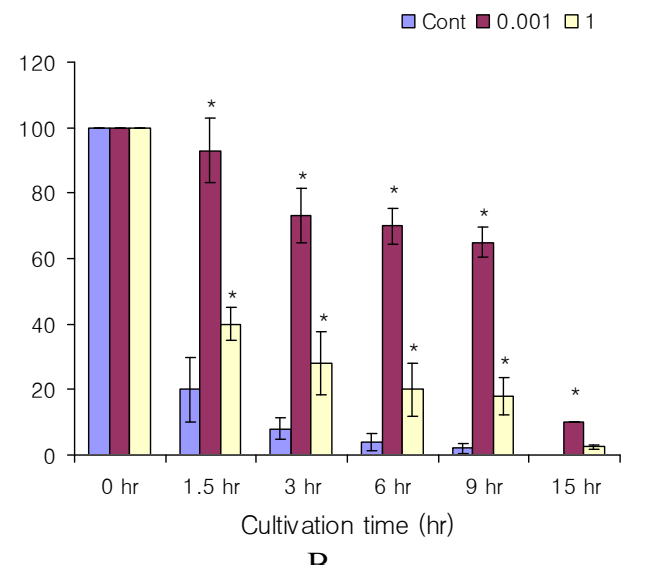

B

Fig. 2. cGMP antagonist Rp-8-Br-cGMP had opposite effect to cGMP agonist both in cumulus-enclosed oocytes (A) and denuded oocytes (B). GV oocytes were treated with $0.001 \mathrm{mM}$ or $1 \mathrm{mM} \mathrm{Rp}$ 8-br-cGMP combined with $750 \mu \mathrm{M}$ guanosine for $15 \mathrm{hr}$ and nuclear status were determined under the investigated microscope (Nomarski DIC modulated) at $0 \mathrm{hr}, 1.5 \mathrm{hr}, 3 \mathrm{hr}, 6 \mathrm{hr}, 9 \mathrm{hr}$ and $15 \mathrm{hr}$. GV; germinal vesicle, Cont; control.*: $P<0.05$ versus control.

of culture (Fig. 3). At $15 \mathrm{hr}$ of culture, the GV arrest percentages were $0 \%$ both control and $1 \mathrm{M}$ Rp-pCPT-8-BrcGMP, and $23 \%$ at $1 \mathrm{mM}$ Rp-pCPT-8-Br-cGMP. In cumulus-enclosed oocytes, the GV arrest effect is similar between Rp-8-Br-cGMP and Rp-pCPT-8-Br-cGMP. In denuded oocyte, the GV arrest percentages after $6 \mathrm{hr}$ of culture were $40 \%$ at control and $73 \%$ both in $1 \mathrm{mM}$ and 1 M Rp-pCPT-8-Br-cGMP. At 15 hr of culture, the GV arrest

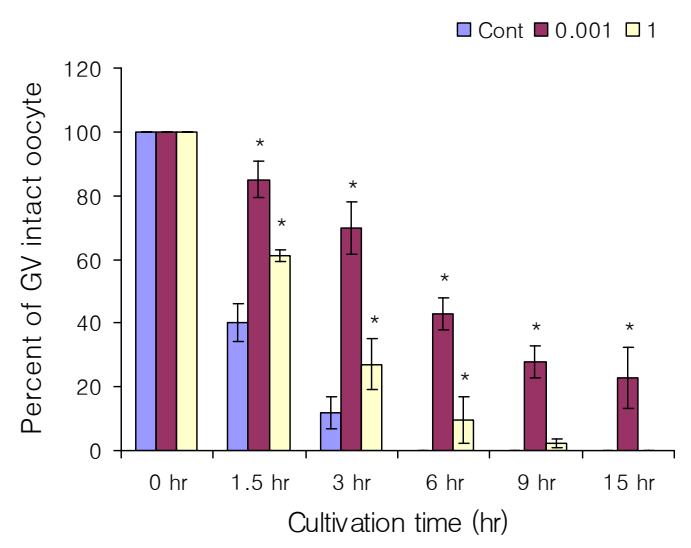

A

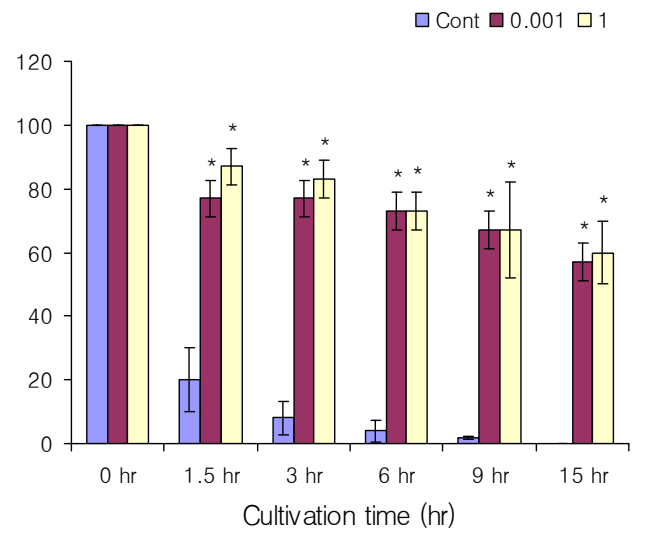

B

Fig. 3. Effects of cGMP antagonist Rp-pCPT-8-BromocGMP on GV arrest in cumulus-enclosed oocytes (A) and denuded oocytes (B). GV oocytes were treated with $0.001 \mathrm{mM}$ or $1 \mathrm{mM}$ Rp-pCPT-8br-cGMP combined with $750 \mu \mathrm{M}$ guanosine for 15 $\mathrm{hr}$ and nuclear status were determined under the investigated microscope (Nomarski DIC modulated) at $0 \mathrm{hr}, 1.5 \mathrm{hr}, 3 \mathrm{hr}, 6 \mathrm{hr}, 9 \mathrm{hr}$ and $15 \mathrm{hr}$. GV; germinal vesicle, Cont; control. *: $P<0.05$ versus control.

percentages were $0 \%$ at control, $57 \%$ at $1 \mathrm{mM} \mathrm{Rp-pCPT-8-}$ Br-cGMP, and $60 \%$ at 1 M Rp-pCPT-8-Br-cGMP. When compared with the results of cumulus-enclosed oocytes and denuded oocytes, the inhibitory effects of Rp-pCPT-8Br-cGMP severe in denuded oocytes (Fig. 3).

\section{DISCUSSION}

Fertility of female is depending on the quantity and 
quality of follicles, and the getting a competence for development in the oocyte is critical for oncogenesis. Oocytes have to stay until ovulation at GV intact status, prophase I of meiosis. A few of cellular molecules are known to be involved in this arrest. The well-known molecules are cAMP and its metabolic materials. Cotreatment of FSH and adenosine markedly inhibits the GVB of CEO in a dose-dependent manner (Mille \& Behrman, 1986). Recently, we reported about the possible roles of adenosine and adenosine receptor-mediated calcium signaling in GV arrest of oocytes enclosed with cumulus (Hwang \& Cheon, 2013). It supports the role of calcium in cAMP action (Powers \& Paleos, 1982; Preston et al., 1987). On the other hand, cyclic GMP also is also suggested as a mediator for cAMP regulation in oocyte. cGMP inhibit cAMP hydrolysis through PDE3A (Norris et al., 2009; Vaccari et al., 2009).

The cGMP levels in follicle are uniformly high (about 2$4 \mu \mathrm{M})$. Its levels are decreased to $100 \mathrm{nM}$ by $\mathrm{LH}$ surge. The level of cGMP in oocyte is also decreased uniformly to about $100 \mathrm{nM}$ and this decrease causes of meiotic restart (Shuhaibar et al., 2015). In follicle cGMP producing guanylyl cyclase natriuretic peptide receptor 2 (NPR2, guanylyl cyclase B) is present in all of the granulosa cells, but not in the oocyte (Jankowski et al., 1997; Zhang et al., 2010; Robinson et al., 2012; Egbert et al., 2014). Those are suggested that cGMP is originated from follicle cells. The cell permeable cGMP analog, 8-Br-cGMP inhibits GVB with concentration-dependent manners both in cumulusenclosed oocytes and denuded oocyte. The effects of 8-BrcGMP were stronger in cumulus-enclosed oocytes than denuded oocytes. Its inhibitory effects were continued until $15 \mathrm{hr}$ of culture in denuded oocytes. Interestingly, the cumulus decreased the effects of cGMP on the GV arrest. Such a responsibility of oocyte to cGMP suggest that cumulus may modulate the cGMP effects on GVB arrest.

The antagonists of cGMP in cellular signaling, Rp-8-Br-
cGMP and Rp-pCPT-8-Br-cGMP were showed opposite effect to 8-Br-cGMP. However, its effects were specific to the concentration of Rp-8-Br-cGMP in cumulus-enclosed oocytes but not in denuded oocytes. In denuded oocytes, the spontaneous maturation processed dependently to the concentration of Rp-8-Br-cGMP. In cumulus-enclosed oocytes, the effects of Rp-pCPT-8-Br-cGMP also had a similar pattern with the Rp-8-Br-cGMP concentration. In denuded oocytes, Rp-pCPT-8-Br-cGMP was significantly inhibited GVB in all groups compared with control, though its GVB inhibitor effect were less than 8-Br-cGMP. The responsibility to the Rp-pCPT-8-Br-cGMP and Rp-8Br-cGMP are typically different between cumulus-enclosed oocyte and denuded oocytes. However, interestingly Rp-pCPT-8-Br-cGMP inhibited severely more than Rp-8Br-cGMP at $1 \mathrm{mM}$ but not $1 \mathrm{M}$. Such differences between antagonists for cGMP may be originated from the difference of the affinity to the target molecule. Based on them, it means that the sensitivity for GV arrest to cGMP may be modified by cumulus cells.

The cGMP transported from granulosa cells to oocyte through gap junction has been suggested as a key factor for $\mathrm{GV}$ arrest. Based on the results, we know that the responsibility to agonist or antagonist is modified by the cumulus. The GV arrest was maintained in denuded oocyte by 8 -Br-cGMP significantly compared with Rp-8-BrcGMP or Rp-pCPT-8-Br-cGMP. Put together, it suggests that the role of cGMP for spontaneous GVB is modulated by cumulus.

\section{ACKNOWLEDGEMENTS}

This research was supported by a grant of the Korea Health Technology R\&D Project through the Korea Health Industry Development Institute (KHIDI), funded by the Ministry of Health \& Welfare, Republic of Korea (grant number: H16C1085). 


\section{REFERENCES}

Cheon YP (2004) Guanosine regulates germinal vesicle breakdown (GVBD) in mouse oocytes. Reprod Dev Biol 28:267-273.

Dutta S, Burks DM, Pepling ME (2016) Arrst at the diplotene stage of meiotic prophase I is delayed by grogesterone but is not required for primodial follicle formation in mice. Reprod Biol Endocrinol 14:82

Egbert JR, Shuhaibar LC, Edmund AB, Wan Helden DA, Robinson JW, Uliasz TF, Baena V, Geerts A, Wunder F, Potter LR, Jaffe LA (2014) Dephosphorylation and inactivation of NPR2 guanylyl cyclase in granulosa cells contributes to the LH-induced decrease in cGMP that causes resumption of meiosis in rat oocytes. Development 141:3594-3604.

Eppig JJ, Ward-Bailey PF, Coleman DL (1985) Hypoxanthine and adenosine in murine ovarian follicular fluid: concentrations and activity in maintaining oocyte meiotic arrest. Biol Reprod 33:1041-1049.

Erickson GF, Sorenson RA (1974) In vitro matruation of mouse oocytes isolated from late, middle, and preantral Graafian follicles. J Exp Zool 190:123-127.

Hambleton R, Krall J, Tikishvili E, Honeggar M, Ahmad F, Manganiello VC, Movsesian MA (2005) Isoforms of cyclic nucleotide phosphodiesterase PDE3 and their contribution to cAMP hydrolytic activity in subcellular fractions of human myocardium. J Biol Chem 280: 39168-39174.

Hubbard CJ (1980) Ovarian cAMP and cGMP flucturations in the hamster during the oestrous cycle. J Reprod Fertil 59:351-355.

Hubbard CJ, Terranova PF (1982) Inhibitory action of cyclic guanosine 5'-phosphoric acid (GMP) on oocyte maturation: dependence on an intact cumulus. Biol Reprod 26:628-632.

Hwang H, Cheon YP (2013) Adenosine receptors mediated intracellular calcium in cumulus cells involved in the maitenance of first meiotic arrest. Dev Reprod 17:141147.

Jankowski M, Reis AM, Mukaddam-Daher S, Dam TV, Farookhi R, Gutkowska J (1997) C-type natriuretic peptide and the guanylyl cyclase receptors in the rat ovary are modulated by the estrous cycle. Biol Reprod 56:59-66.

Jones KT (2008) Meiosis in oocytes: predisposition to aneuploidy and its increased incidence with age. Hum Reprod update 14:143-158.

Mehlmann LM (2005) Oocyte-specific expression of Gpr3 is required for the maintenance of meiotic arrest in mouse oocytes. Dev Biol 288:397-4040.

Norris RP, Ratzan WJ, Freudzon M, Mahlmann LM, Krall J, Movsesian MA, Wang H, Ke H, Nikolaev VO, Jaffe LA (2009) Cyclic GMP from the surrounding somatic cells regulates cyclic AMP and meiosis in the mouse oocyte. Development 136:1869-1878.

Pincus G, Enzmann EV (1935) The comparative behavior of mammalian eggs in vivo and in vitro. J Exp Med 62:665-675.

Powers RD, Paleos GA (1982) Combined effects of calcium and dibutyryl cyclic AMP on germinal vesicle breakdown in the mouse oocyte. J Reprod Fertil 66:1-8.

Preston SL, Parmer TG, Behrman HR (1987) Adenosine reverses calcium-dependent inhibition of follicle-stimulating hormone action and induction of maturation in cumulusenclosed rat oocytes. Endocrinology 120: 1346-1353.

Robinson JW, Zhang M, Shuhaibar LC, Norris RP, Geerts A, Wunder F, Eppig JJ, Potter LR, Jaffe LA (2012) Luteinizing hormone reduces the activity of the NPR2 guanylyl cyclase in mouse ovarian follicles, contributing to the cyclic GMP decrease that promotes resumption of meiosis in oocytes. Dev Biol 366:308-316.

Shuhaibar LC, Egbert JR, Norris RP, Lampe PD, Nikolaev VO, Thunemann M, Wen L, Feil R, Jaffe LA (2015) Intracellular signaling via cyclic GMP diffusion th- 


\section{cGMP in GVB}

rough gap junctions restarts meiosis in mouse ovarian follicles. Proc Natl Acad Sci U S A 112:5527-5532.

Vaccari S, Weeks II JL, Hsieh M, Menniti FS, Conti M (2009) Cyclic GMP signalings is involved in the luteinizing hormone-dependent meiotic maturation of mouse oocytes. Biol Reprod 81:595-604.

Zhang M, Su Y-Q, Sugiura K, Xia G, Eppig JJ (2010) Granulosa cell ligand NPPC and its receptor NPR2 maintain meiotic arrest in mouse oocytes. Science 330: 366-369. 